\title{
Heat losses in power boilers caused by thermal bridges
}

\author{
Monika Kocot $^{1, *}$, Stanistaw Lopata $^{2, * *}$ and Zbigniew Plutecki ${ }^{3}$ \\ ${ }^{1}$ Heat not Lost Sp. z o.o. ul. Górnych Wałów 7, 44-100 Gliwice, Poland \\ ${ }^{2}$ Cracow University of Technology, Institute of Thermal Power Engineering, al. Jana Pawła II 37, \\ 31-864 Kraków, Poland \\ ${ }^{3}$ Opole University of Technology, Department of Innovative Technological Processes, ul. Ozimska \\ 75, 45-370 Opole, Poland
}

\begin{abstract}
In this article the analysis of heat losses caused by thermal bridges that occur in the steam boiler OP-140 is presented. Identification of these bridges were conducted with use of thermographic camera. Heat losses were evaluated based on methodology of VDI 4610 standard, but instead of its simplified equations, criterial equations based on Nusselt number were used. Obtained values of annual heat losses and heat flux density corresponding to the fully insulated boiler surfaces were compared to heat losses generated by thermal bridges located in the same areas. The emphasis is put on the role of industrial insulation in heat losses reduction.
\end{abstract}

\section{Introduction}

The amount of heat losses in power boilers has a significant influence on their capability to process energy. The improvement of energy processing efficiency is achievable through:

- optimization of coal incineration processes,

- obtaining higher steam parameters,

- minimization of static heat losses.

Among the main causes of heat losses in power boilers are bad technical condition, improper installation or a complete lack of thermal insulation. Previously installed thermal insulations were performed according to the now withdrawn ordinance of the Minister of Economy dated September 171999 concerning safety and hygiene of work with power equipment and installations, which stated that the external surface temperature of the insulation layer should not exceed $60^{\circ} \mathrm{C}$ - thus protecting workers from heat-related injuries [1]. In most cases, such insulation had nothing to do with heat losses reduction nor with reaching the maximum return on investment at potentially lowest losses of energy. Nowadays growing energy prices, regulations targeted at reduction of carbon dioxide emissions as well as growing awareness of energy manufacturers create favourable environment for:

\footnotetext{
* Corresponding author: monika.kocot@hnl.pl

** Corresponding author: lopata@mech.pk.edu.pl
} 
- selection of the economic thickness of insulation,

- modernizations, e.g. isolating of installations and elements that were not isolated before,

- replacement of damaged insulation.

It is commonly known, that insulation of industrial installations and machines is performed to achieve certain goals, such as:

- minimization of heat transfer to the environment (reduction of heat losses),

- prevention of thermal deformations,

- reduction of temperature loss of the operating medium flowing through the vessels,

- control over the temperature of an operating medium,

- prevention of steam condensation on the vessel's surface,

- protection of health and providing safety for the workers (e.g. by heat-related injuries prevention).

Currently in Poland isolation of industrial installations is also regarded as one of the most important and efficient tools of energy efficiency improvement [2].

Additionally, on May 202016 the Energy Efficiency act was adopted by the Polish parliament, which regulates activities of enterprises from the energy sector by setting a number of obligations and restrictions, such as [3]:

- obligation to perform actions targeted at energy efficiency improvement resulting in $1,5 \%$ savings of electric, heat or natural gas energy measured in toe (tonne of oil equivalent) sold to end-users on the territory of Poland per annum,

- gradual restriction of compensation payment opportunities - certain payment thresholds will be introduced,

- obligation to contract out or conduct energy audits every four years (concerns enterprises defined by the Freedom of Economic Activity Act as non-SMEs).

Obligations defined by legislation as well as benefits resulting from energy efficiency improvement, boost popularity of thermal modernizations.

\section{Technical characteristics of the analysed power boiler}

The analysis has been conducted on the OP-140 power boiler operating at one of the national power plants. This boiler is coal-fired and the biomass in the participation $15 \%$. It cooperates with a similar boiler and each of them generates 145 tons of steam per hour. For steam characteristics are: temperature of $540{ }^{\circ} \mathrm{C}$ and pressure of $13,5 \mathrm{MPa}$. It is channelled by pipelines of an integrated collector system to a pass-out condensing turbine used for heating purposes. The first launch of the analysed power boiler took place in 1976. The boiler has a typical two-pass configuration: radiant surfaces are located above the furnace in the first pass ( $\mathrm{I}$ - absorb heat by thermal radiation), and convective surfaces are arranged in the second pass (II - absorb heat via a fluid i.e. gas). These flue gas ducting are connected by a horizontal gas duct (the fire-bridge) at the top of boiler.

The internal surface of the analysed boiler is covered with isolation that consists of specific insulation layer and protective coating. To the present this isolation had been in use for 39 years [4]. It was made of mineral wool mats. Those mats were made of several layers of thickness $100 \mathrm{~mm}+2 \times 50 \mathrm{~mm}$, with an average density of $100 \mathrm{~kg} / \mathrm{m}^{3}$. Additionally the isolation contained: bearing structure, galvanized mesh, steel sheet coating of thickness 1.0 $\mathrm{mm}$, in some places flat and in some places trapezoidal. Condition of the isolation presented on the attached images (Figure 1) had not been verified for a long time and a visual inspection revealed a number of irregularities, including noticeable chipping, discontinuities and corrosion damages. 

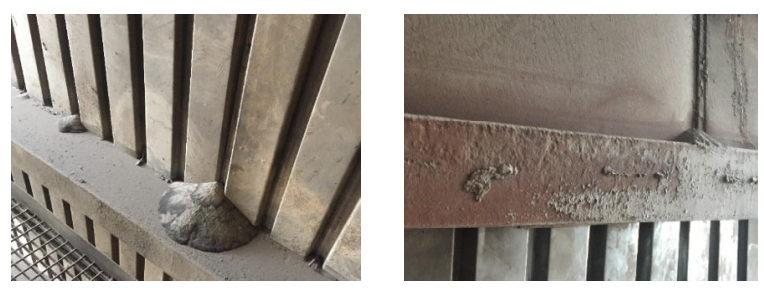

Figure 1. Damage of the isolation layer spotted on the analysed power boiler OP-140.

\section{Analysis of generated heat losses}

\subsection{Thermographic analysis of the boiler}

Thermographic examination of the boiler was conducted in November 2015 between 8 a.m. and $3 \mathrm{p} . \mathrm{m}$. The temperature of the external environment of the boiler varied at different altitudes from $+12{ }^{\circ} \mathrm{C}$ (level $+0,00 \mathrm{~m}$ ) up to around $40{ }^{\circ} \mathrm{C}$ (level $+35,00 \mathrm{~m}$ ). The examination was carried out while the boiler was operating at nearly nominal heat output (nominal power). The boiler's surface temperature and thermal bridges surface temperature were studied with the use of Flir E60 thermographic camera and a multifunctional device with sensors (for measurements temperatures of the surfaces and liquid environments). This allowed to diagnose the places of occurrence of thermal bridges simultaneously.

Due to the boiler's construction and the varying environmental temperature, the installation was divided in zones (for the needs of calculation and analysis). Numbers and descriptions are given (and altitudes in brackets):

- zone 1 - fragment includes the $1^{\text {st }}$ pass (I) of the boiler $(0,00 \mathrm{~m} \div 8,10 \mathrm{~m})$,

- zone 2 - fragment includes the $1^{\text {st }}$ pass (I) of the boiler $(8,10 \mathrm{~m} \div 15,85 \mathrm{~m})$,

- zone 3 - fragment includes the $1^{\text {st }}$ pass (I) of the boiler $(15,85 \mathrm{~m} \div 20,70 \mathrm{~m})$,

- zone 4 - fragment includes the $1^{\text {st }}$ and the $2^{\text {nd }}$ pass (I and II) of the boiler $(20,70 \mathrm{~m} \div$ $27,00 \mathrm{~m})$,

- zone 5 - fragment includes the $2^{\text {nd }}$ pass (II) of the boiler $(15,85 \mathrm{~m} \div 20,70 \mathrm{~m})$,

- zone 6 - fragment includes the $2^{\text {nd }}$ pass (II) of the boiler $(9,30 \mathrm{~m} \div 15,85 \mathrm{~m})$,

- zone 7 - fragment includes the structural ceiling of the boiler space $(27,00 \mathrm{~m} \div 33,00$ $\mathrm{m})$,

- zone 8 - steam drum of boiler (29 m).

Locations of the given zones are presented on figure 2 (along with the overall scheme of the boiler [5]).

The only area which was hard to reach and examine was around the structural ceiling space above the boiler's duct. The temperature between structural beams reached $300{ }^{\circ} \mathrm{C}$ which accompanied by intensive air flows, causing this area physically inaccessible. In addition, this space was isolated only from the outside. Therefore, in order to assure the most optimal isolation in this area, it would be recommended to apply additional of injection isolation or loose mineral wool. 


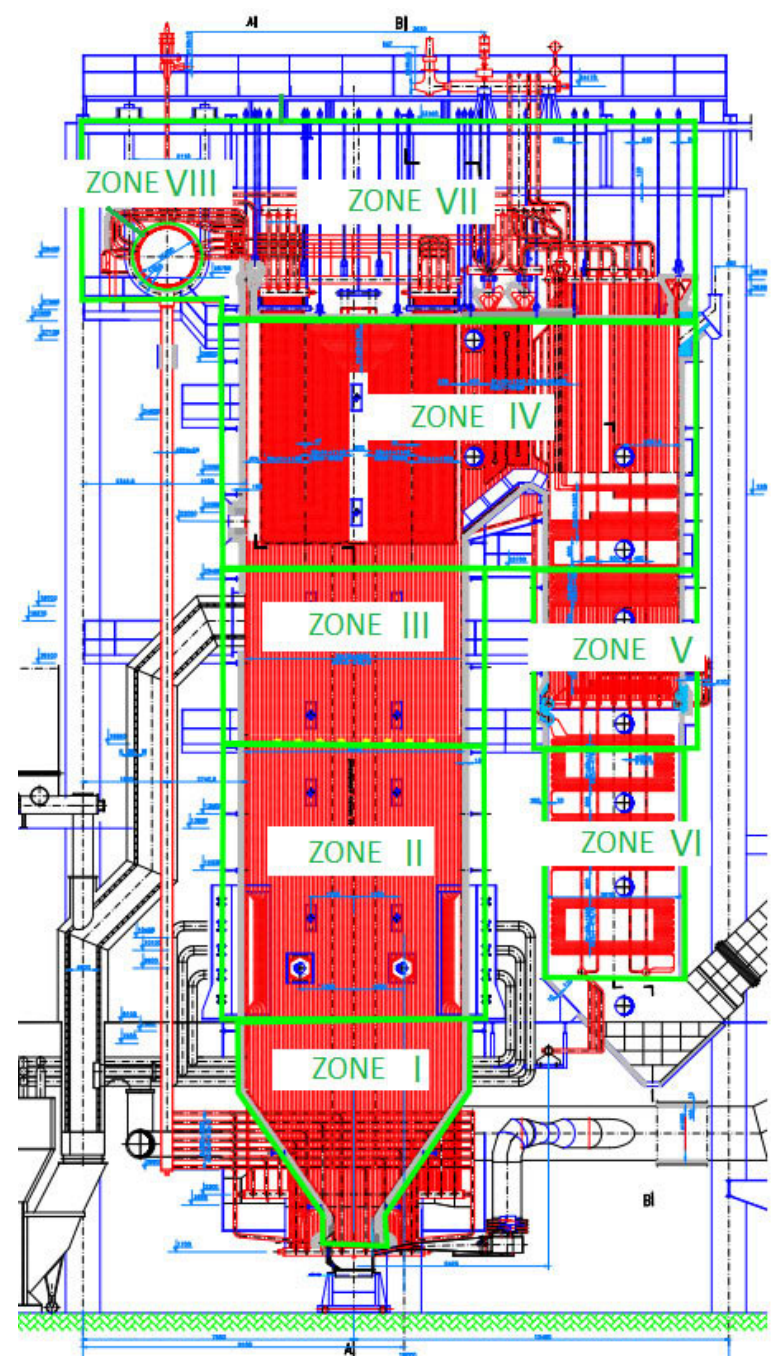

Figure 2. Scheme of the power boiler OP-140 and locations of zones of thermographic analysis.

\subsection{Identification of thermal bridges}

Thermographic examination of the power boiler revealed its thermal bridges and provided an opportunity to further analyse them by classification into relevant categories based on their key features. The following categories of thermal bridges were distinguished [6]:

- operational, resulting from chipping and displacement of specific insulation (occurred mainly on straight surfaces, covering the heat transfer surfaces of the boiler, e.g. in zones of waterwalls panels, reheaters and superheaters),

- structural (constructional), originating from many integrated elements which provide the operational stability of the boiler, such as: built-in sealing rings located on its circumference (on levels: $+7,20 \mathrm{~m},+10,45 \mathrm{~m},+12,33 \mathrm{~m},+13,90 \mathrm{~m}, 15,93 \mathrm{~m},+18,10 \mathrm{~m}$, $+20,45 \mathrm{~m},+22,80 \mathrm{~m},+24,65 \mathrm{~m},+26,50 \mathrm{~m}$ and $+27,95 \mathrm{~m})$ as well as e.g. inspection hatches, valves, thermowell of the measuring equipments (these elements usually remain uninsulated), 
- assembly-related, caused by the improper isolation assembly (e.g. excluding bypassing the rules, rushed work, lack of supervision, which might lead to improper thickness, uneven distribution or even a complete lack of insulation).

Figures 3-5 demonstrate the abovementioned types of thermal bridges identified on the analysed boiler (they are showing their thermographic images and their real-life photographs). White dashed lines create boundaries for which Flir Tools + has calculated average temperatures that were later used for heat loss calculation.

a
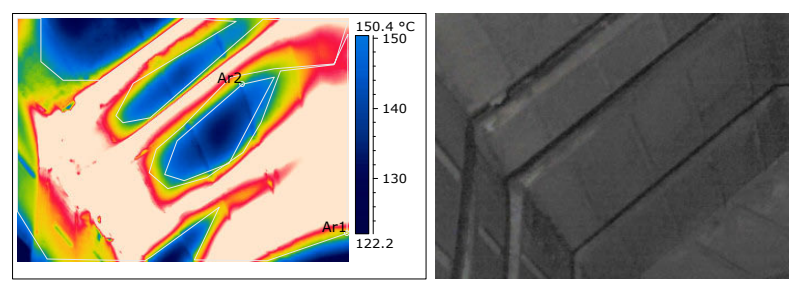

b
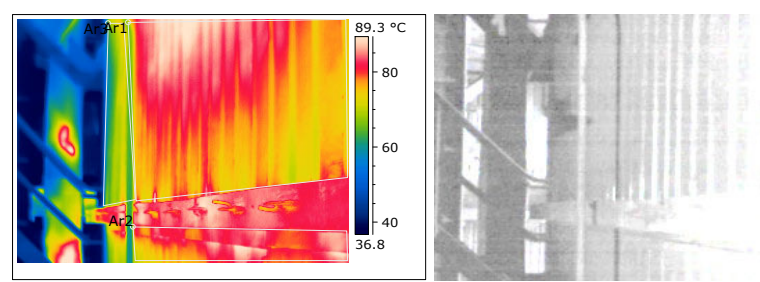

c
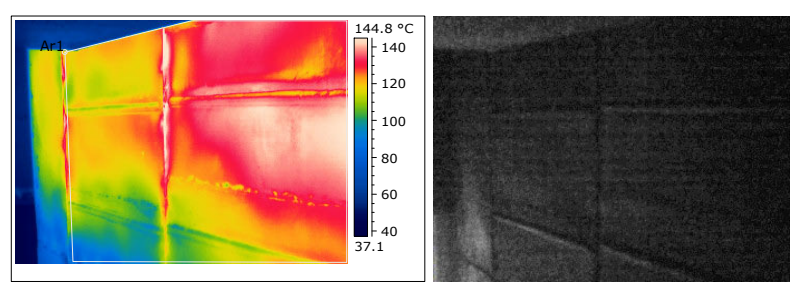

Figure 3. Operational thermal bridges: a - boiler's duct, $\mathrm{b}$ - zone IV, front wall, $\mathrm{c}$ - zone VIII, left wall.

a
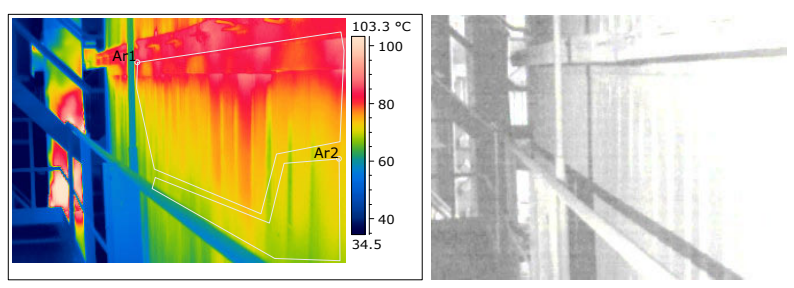
$\mathrm{b}$

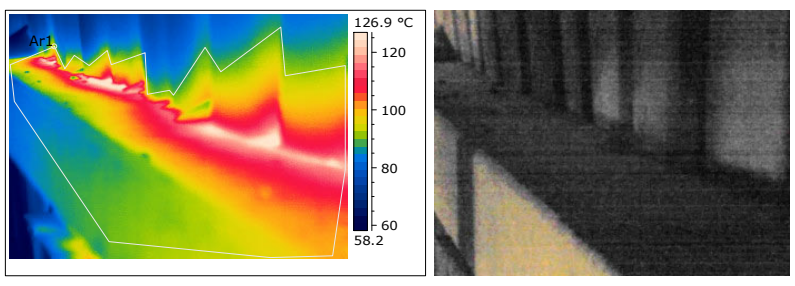

c

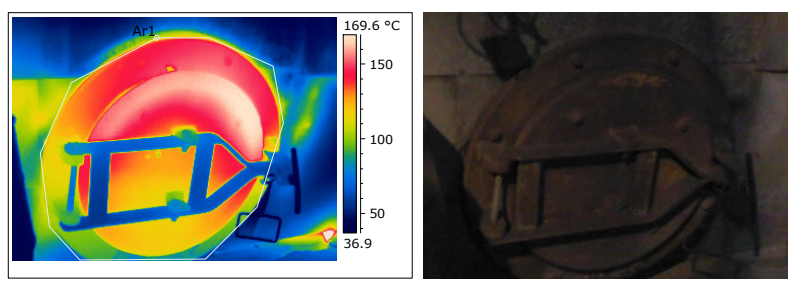

d
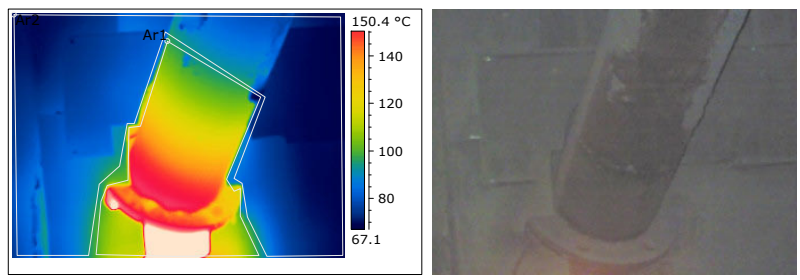

Figure 4. Structural thermal bridges: a - zone IV, front wall, b - zone IV, left wall, c - zone VI, right wall (inspection hatch), $d$ - zone III (OFA nozzle).
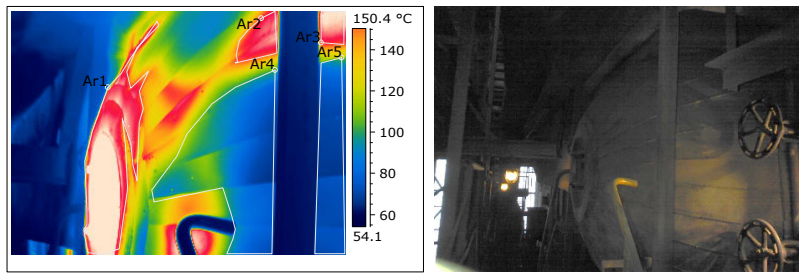

Figure 5. Assembly-related thermal bridge: the bottom of the boiler drum.

\subsection{Heat losses calculation}

\subsubsection{Defining average temperatures of the analysed surfaces of the boiler}

A thorough analysis of the thermographic images enabled us to define average temperatures of insulation coatings and at chosen locations of thermal bridges. The used equipment (Flir Tools + software) allowed us to select a region and calculate the average temperatures for it. The program also provides an opportunity to introduce parameters that might have influence on the interpretation of thermographic images. These are e.g.: emissivity coefficient, reflected temperature RTC, environmental temperature, air flow velocity, as well as distance between the camera and a measured object. All mentioned parameters were measured during the examination with the use of a specified tape Introl HB, that has a 
constant emissivity coefficient, Lambert radiator and a set of thermometers accompanied by sensors designed to measure temperatures of liquids and surfaces. All surfaces where heat exchange occurs, including parts of thermal bridges, along with their obtained average temperatures are listed in Table 1 [7].

Table 1. Heat exchange areas and corresponding to them average temperatures (of the insulation coating in selected boiler zones and thermal bridges).

\begin{tabular}{|c|c|c|c|c|}
\hline Name & $\mathbf{A}_{\mathbf{1}}, \mathbf{~ m}^{\mathbf{2}}$ & $\mathbf{T}_{\mathbf{1}},{ }^{\mathbf{o}} \mathbf{C}$ & $\mathbf{A}_{\mathbf{2}}, \mathbf{~ m}^{\mathbf{2}}$ & $\mathbf{T}_{\mathbf{2}},{ }^{\mathbf{}} \mathbf{C}$ \\
\hline Zone 1 & 155 & 57 & 35 & 100 \\
\hline Zone 2 & 204 & 77 & 42 & 82 \\
\hline Zone 3 & 131 & 76 & 43 & 78 \\
\hline Zone 4 & 331 & 84 & 62 & 95 \\
\hline Zone 5 & 70 & 69 & 25 & 79 \\
\hline Zone 6 & 115 & 60 & 25 & 75 \\
\hline Zone 7 & 290 & 84 & - & - \\
\hline Zone 8 & 63 & 93 & - & - \\
\hline $\begin{array}{c}\text { Other thermal } \\
\text { bridges (measuring } \\
\text { equipment, } \\
\text { inspection hatch, } \\
\text { bottoms etc.) }\end{array}$ & - & - & 15 & 120 \\
\hline
\end{tabular}

Notions used in Table 1: $\mathrm{A}_{1}$ - are of the isolation surface, $\mathrm{m}^{2}, \mathrm{~A}_{2}$ - area of the thermal bridge, $\mathrm{m}^{2}, \mathrm{~T}_{1}$ - insulation coating temperature, ${ }^{\circ} \mathrm{C}, \mathrm{T}_{2}$ - thermal bridge temperature, ${ }^{\circ} \mathrm{C}$.

\subsubsection{Methodology of heat losses calculation}

Thermographic images of heat distribution in each zone of the boiler were made, on which temperature maps on the surfaces of the boiler and thermal bridges are clearly distinguishable (e.g. on figures 3-5). Then calculations of heat losses were made:

- through the isolated surface of the boiler taking into account measured temperatures of insulation coatings,

- through identified structural, assembly-related and operational thermal bridges.

Heat losses calculations were done based on the norm VDI 4610 [8]. It enables the evaluation of heat losses generated by the isolation and thermal bridges. Used quantitative dependencies were simplified with regard to the analysed object. The overall flow of heat losses generated by an installation was calculated by using the following equation:

$$
Q=\sum_{i=1}^{n} Q_{i}
$$

where:

$Q$ - the overall heat flow, W,

$Q_{i}$ - the heat loss flow generated by an i-th component of the system (in a given case - by the zone of a boiler), W.

Heat losses of a chosen zone of a boiler:

$$
Q_{i}=Q_{W D, i}+Q_{W B, i}
$$


where:

$Q_{W D, i}$ - heat loss flow generated by the i-th standard element of a component, W,

$Q_{W B, I}$ - heat loss flow generated by the i-th thermal bridge or by the i-th uninsulated part of the component, $\mathrm{W}$.

In case of the boiler the heat losses flow through the chosen zone is calculated with taking into account of heat losses originated by thermal insulation as well as through regular and irregular thermal bridges. The following equation was used:

$$
\begin{aligned}
& Q_{i}=q_{p} \cdot A_{m}+\sum_{j=1}^{m} Q_{W B d, i, j}+\sum_{y=1}^{m} Q_{W D-B T, i, y}= \\
& {\left[\frac{1}{R_{s i}+R_{S c}+R_{s e}} \cdot A_{m}+\sum_{j=1}^{m}\left(k \cdot A_{m}\right)_{W B d, i, j}+\sum_{y=1}^{m}\left(k \cdot A_{m}\right)_{W D-B T, i, y}\right] \cdot \Delta \vartheta_{i}=} \\
& {\left[\frac{1}{\frac{1}{\alpha_{w}}+\frac{G r_{s c}}{\lambda_{s c}}+\frac{G r_{l z}}{\lambda_{i z} \cdot a}+\frac{G r_{p l}}{\lambda_{p l}}+\frac{1}{\alpha_{k}+\alpha_{r}}} \cdot A_{m}+\right.} \\
& \sum_{j=1}^{m}\left(\frac{1}{\frac{1}{\alpha_{w}}+\frac{G r_{s c}}{\lambda_{s c}}+\frac{1}{\alpha_{k}+\alpha_{r}}} \cdot A_{m}\right)_{W B d i, j}+ \\
& \left.\sum_{y=1}^{m}\left(\frac{1}{\frac{1}{\alpha_{w}}+\frac{G r_{s c}}{\lambda_{s c} \cdot a}+\frac{G r_{i z}}{\lambda_{i z}}+\frac{G r_{p l}}{\lambda_{p l}}+\frac{1}{\alpha_{k}+\alpha_{r}}} \cdot A_{m}\right)_{W D-B T i, y}\right] \cdot \Delta \vartheta_{l}
\end{aligned}
$$

where:

$q_{p}$ - heat loss flow generated by thermal insulation, per square meter (heat flux density), $\mathrm{W} / \mathrm{m}^{2}$,

$A_{\mathrm{m}}$ - heat exchange area, $\mathrm{m}^{2}$,

$Q_{W B d, i, j}$ - heat loss flow generated by irregular thermal bridges occurring in insulation (structural and assembly-related thermal bridges), $\mathrm{W}$

$Q_{W D-B T, i, y}$ - heat loss flow generated by the isolated component of the object (operational thermal bridges), $\mathrm{W}$,

$R_{s i}$ - heat resistance of the internal side of the object, $\left(\mathrm{m}^{2} \mathrm{~K}\right) / \mathrm{W}$,

$R_{s c}$ - heat resistance of the object's wall, $\left(\mathrm{m}^{2} \mathrm{~K}\right) / \mathrm{W}$,

$R_{s e}$ - heat resistance of the external side of the object, $\left(\mathrm{m}^{2} \mathrm{~K}\right) / \mathrm{W}$,

$k$ - heat transfer coefficient, $\mathrm{W} /\left(\mathrm{m}^{2} \mathrm{~K}\right)$,

$\Delta \vartheta_{l}$ - difference of temperatures between the operating medium and the external environment, ${ }^{\circ} \mathrm{C}$,

$\alpha_{w}$ - convective heat transfer coefficient of the internal side of the object, $\mathrm{W} /\left(\mathrm{m}^{2} \mathrm{~K}\right)$,

$\alpha_{k}$ - convective heat transfer coefficient, $\mathrm{W} /\left(\mathrm{m}^{2} \mathrm{~K}\right)$,

$\alpha_{r}$ - radiative heat transfer coefficient, $\mathrm{W} /\left(\mathrm{m}^{2} \mathrm{~K}\right)$, 
$\lambda$ - thermal conductivity coefficient (in subscripts, correspondingly: sc - the wall of the object, iz - isolation, $\mathrm{pl}$ - isolation coating), $\mathrm{W} /(\mathrm{mK})$,

$G r$ - thickness (in subscripts, correspondingly: sc - the wall of the object, iz - isolation, pl - isolation coating), $\mathrm{m}$, a - deterioration factor of insulation, - .

All convectional heat transfer coefficients were calculated with regard to the heat exchange process between the external surface of the boiler and the surrounding air using criterial equations, allowing to determinate the Nusselt number. In case of the analysed power boiler OP-140 a free convection takes place. Air flows upwards along the the boiler's surface. This phenomenon is caused by different air densities on different altitudes. No horizontal air currents were registered at the walls of the object. Depending on the geometry of the object the Nusselt number may be derived from the empirical equations, e.g. from Pchelkin's model (examples are presented in Table 2) [9].

Table 2. Empirical equations for the chosen types of convectional heat transfer.

\begin{tabular}{|c|c|}
\hline Convection & $\begin{array}{c}\text { Type of convection, } \\
\text { Nusselt criterion, } \\
\text { Range of applicability, } \\
\text { Calculations temperature, }{ }^{\circ} \mathrm{C}\end{array}$ \\
\hline \multirow{4}{*}{$\left.\right|_{x}$} & $\begin{array}{c}\text { Free, laminar } \\
N u_{x}=0,676 \cdot \operatorname{Pr}^{0,5} \cdot\left(0,861+\operatorname{Pr}_{p}\right)^{-0,25} \cdot\left(0,25 \cdot G r_{x p}\right)^{0,25} \\
10^{4}<G r_{x p} \operatorname{Pr}_{p}<6 \cdot 10^{10} \\
t=t_{p}=t_{\infty} ; \quad \operatorname{Pr} r_{p}=\operatorname{Pr}\left(t_{p}\right) ; \quad G r_{p}=G r\left(t_{p}\right)\end{array}$ \\
\hline & $\begin{array}{c}\text { Free, laminar } \\
N u_{h}=0,902 \cdot \operatorname{Pr}^{0,5} \cdot\left(0,861+\operatorname{Pr}_{p}\right)^{-0,25} \cdot\left(0,25 \cdot G r_{h p}\right)^{0,25} \\
10^{4}<G r_{h p} P r_{p}<6 \cdot 10^{10} \\
t=t_{p}=t_{\infty} ; \quad \operatorname{Pr} r_{p}=\operatorname{Pr}\left(t_{p}\right) ; \quad G r_{p}=G r\left(t_{p}\right) \\
\end{array}$ \\
\hline & $\begin{array}{c}\text { Free, turbulent } \\
\begin{array}{c}N u_{x}=0,030 \cdot G r_{x t}{ }^{0,4} \cdot P r_{t}^{0,47} \cdot\left(1+0,494 \cdot P r_{t}^{0,66}\right)^{-0,4} \\
6 \cdot 10^{10}<G r_{x t} \cdot \operatorname{Pr} t \\
t=t_{t}=0,5\left(t_{p}+t_{g}\right) ; \quad \operatorname{Pr} r_{t}=\operatorname{Pr}\left(t_{t}\right) ; \quad G r_{t}=G r\left(t_{t}\right)\end{array}\end{array}$ \\
\hline & $\begin{array}{c}\text { Free, turbulent } \\
N u_{h}=0,025 \cdot G r_{h t}{ }^{0,4} \cdot P r_{t}^{0,47} \cdot\left(1+0,494 \cdot P r_{t}^{0,66}\right)^{-0,4} \\
6 \cdot 10^{10}<G r h t^{*} P r_{t} \\
t=t_{t}=0,5\left(t_{p}+t_{g}\right) ; \quad \operatorname{Pr} r_{t}=\operatorname{Pr}\left(t_{t}\right) ; \quad G r_{t}=G r\left(t_{t}\right)\end{array}$ \\
\hline
\end{tabular}

Notions used in Table 2: Nu - Nusselt number, Pr - Prandtl number, Gr - Grashoff number, $\mathrm{h}, \mathrm{x}$ - according to the drawing in column $1, \mathrm{t}_{\mathrm{g}}$ - medium temperature (e.g. gas), ${ }^{\circ} \mathrm{C}$, $\mathrm{t}_{\mathrm{p}}$ - surface temperature, ${ }^{\circ} \mathrm{C}$.

\subsubsection{Results of calculations}

Total heat losses are calculated as the sum of heat losses that occur regularly on the boiler insulation surface and heat losses generated by thermal bridges. Calculated values of annual heat losses, expressed in GJ/year, for the selected zones of the analysed boiler OP-140 are presented on Figure 6. Heat losses generated without the influence of thermal bridges identified in those areas are presented on Figure 6 simultaneously. Moreover, Figure 6 also illustrates values of heat flow density, expressed in $\mathrm{W} / \mathrm{m}^{2}$ (which are also total and without taking into account thermal bridges). 


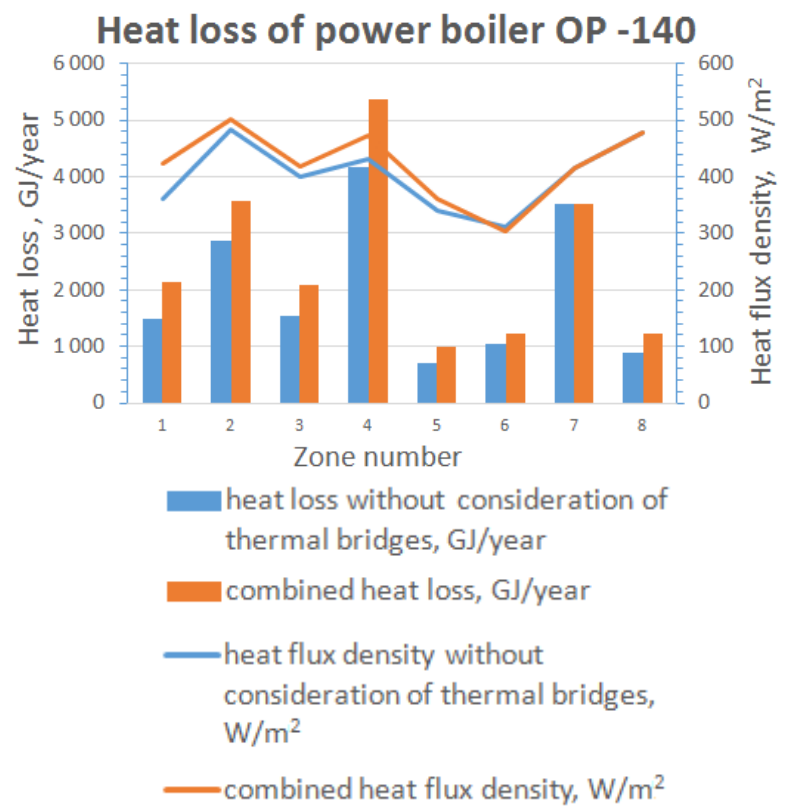

Figure 6. Heat losses and heat flow density (with and without taking into account thermal bridges) calculated for the selected zones of the OP-140 power boiler (at an operating with nominal power).

Analysis of Figure 6 leads to the assumption that thermal bridges located in different parts of power boilers might share up to $30 \%$ of the total heat losses occurring in the installation. Therefore, reducing of the number and influence of thermal bridges will provide a significant energy efficiency improvement. At the same time it will contribute to reduce the negative influence on the natural environment.

\section{Summary and final remarks}

Fuel consumption is directly related to heat losses. The latter also include the thermal bridges, which can be classified as operational, structural and assembly-related. They occur in thermal power equipments and in industrial installations. Heat losses generated by thermal bridges are not always properly evaluated and sometimes they are completely neglected. Such is often the case of structural elements of power boilers. Little attention was paid to them at the end of the previous century. An attitude which has radically changed since then and national environmental policies represent just one of many examples of these changes.

In case of the analysed power boiler OP-140 the most significant heat losses were caused by insulation chipping and improper insulation mounting, that are in fact thermal bridges (ring seals, inspection hatches, tubes and other uninsulated elements etc.). Thermal calculations revealed that by eliminating thermal bridges one may reach energy savings of $15-30 \%$.

\section{References}

1. Regulation of the Minister of Economy of September 171999 on safety and hygiene of work with equipment and power installations (in polish), Dz. U. 1999 r., Nr 80, poz. 912 
2. Announcement of the Ministry of Economy dated December 122012 concerning the detailed list of actions targeted at energy efficiency improvement (in polish), M. P. 2013 r., poz. 15

3. Act of May 202016 about Energy Efficiency (in polish), Dz. U. 2016 r., poz. 831

4. Operating instructions of the energy boiler OP-140 (unpublished)

5. Material companies RAFAKO (Figure concept of OP-140)

6. S. Łopata, Heat not Lost-2015, Energy Efficiency, thermal insulation industry, Ed. Z. Plutecki, Studies and Monographs, 30-36 (Heat not Lost Sp. z o.o., Cracow 2015)

7. M. Kocot, Classification and Heat Loss Analysis of Thermal Bridges in Power Boiler OP-140, Thesis engineering, Cracow University of Technology (2016)

8. German standard VDI 4610: VDI 4610 Blatt 1:2012-12, Energieeffizienz betriebstechnischer Anlagen Wärme - und Kälteschutz (2012)

9. R. Sobociński, Z. Nagórski, T. Kośmicki, Collection of tasks of technical thermodynamics (Publishing Warsaw University of Technology, Warsaw 1996) 